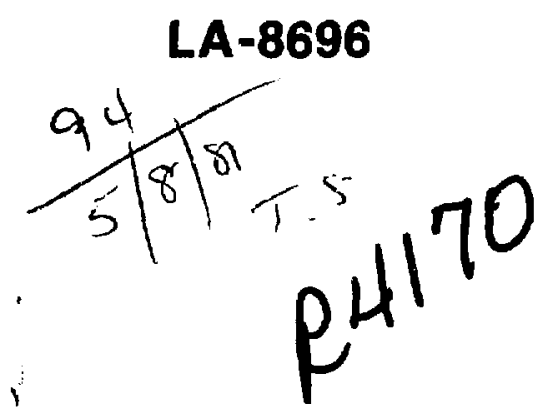

11

Dr. 2615

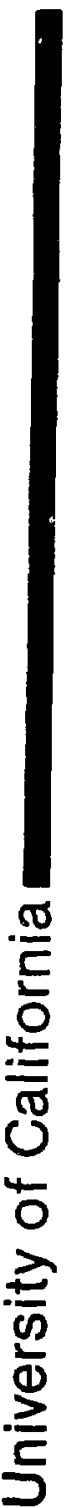

The Deflagration-to-Defonation Transition in Small-Diameter Columns of PETN 


\title{
THE DEFLAGRATION-TO-DETONATION TRANSITION IN SMALL-DIAMETER COLUMNS OF PETN
}

\author{
by
}

\author{
Robert H. Dinegar
}

\begin{abstract}
The transition from deflagration to detonation in pure pentaerythritol tetranitrate (PETN) confined in small-diameter (2-mm) steel columns of three lengths $(6.4,9.6$, and $12.8 \mathrm{~mm}$ ) was examined. These relatively low density pressings of PETN were defiagrated by donor charges of high-density PETN that had been ignited by a hot wire. A dent procisced in an aluminum witness block was the criterion for determining detonation. The transition from burning to detonation occurred in pressings of all three lengths. Detonation velocities sufficient to initiate high-density PETN booster pellets were reached in the $9.6-$ and $12.8-\mathrm{mm}$ pressings.
\end{abstract}

Deflagration-to-detonation transition (DDT) reactions in mixtures of potassium picrate (KP) and pentaerythritol tetranitrate (PETN), as well as in KP mixed with 1,3,5,7- tetranitro-1,3,5,7-tetrazacyclooctane (HMX), have been reported previously, as have reactions in pure PETN and in pure HMX. ${ }^{1,2}$ In this study, we investigated the DDT reaction in PETN in small-diameter $(2-\mathrm{mm})$ steel cylinders of three lengths $(6.4,9.6$, and $12.8 \mathrm{~mm})$. The transition from deflagration to detonation occurs in these columns of PETN.

PETN was the explosive in all parts of the device: the donor charge, the transition-column pressing, and the booster (output) pellet. It was recrystallized from acetone with water and had a permeametrically determined specific surface $\left(S_{0}^{P}\right)$ of $3650 \mathrm{~cm}^{2} / \mathrm{g}$.

The test fixture is shown in Fig. 1. The confining parts are 1120 cold-rolled steel, and the transition column is 1020 cold-rolled steel. The donor-charge holder is a

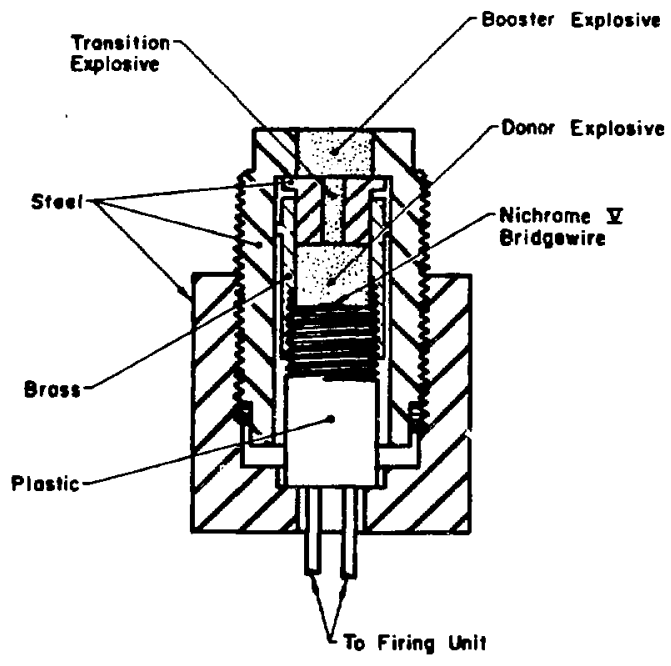

Fig. 1.

DDT assembly (SE-1 type). 
standard SE-1 assembly with brass sleeve and plastic head. The Nichrome V bridgewire $(80 \%$ nickel $+20 \%$ chromium) is $0.050 \mathrm{~mm}$ in diameter and $1.0 \mathrm{~mm}$ long. The resistance of the bridgewire and copper leads is $\sim 0.5$ $\Omega$. The firing voltage was set at $5.0 \mathrm{~V}$, and the firing current was measured as $6.6 \mathrm{~A}$. The criterion for determining if a detonation had occurred was the production of a dent in an aluminum witness block.

The results at a transition-charge pressing density ( $p$ ) of $1.2 \mathrm{~g} / \mathrm{cm}^{3}$ are shown in Fig. 2. They are strongly

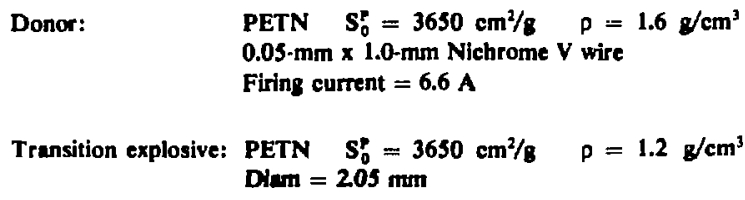

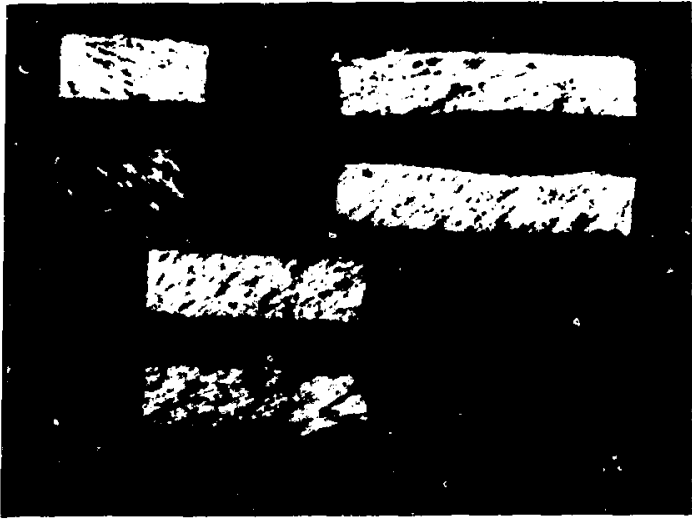

End confinement: Air

Length: $\quad 6.4 \mathrm{~mm} \quad 9.6 \mathrm{~mm} \quad 12.8 \mathrm{~mm}$

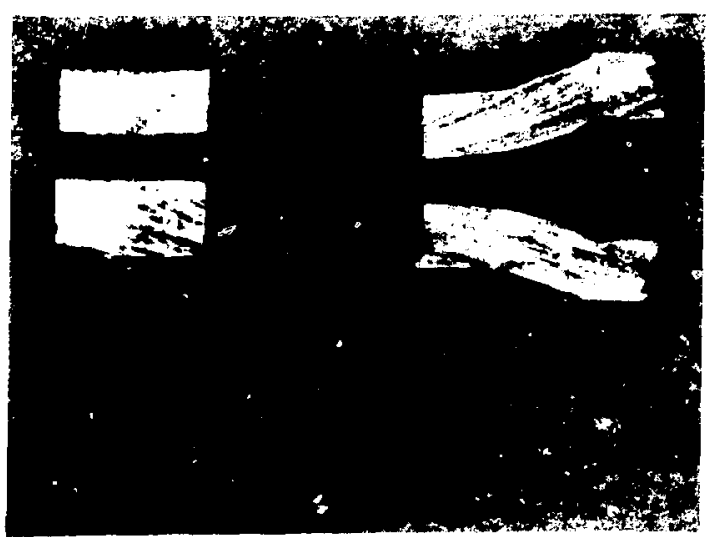

End confinement:

Length: $\quad 6.4 \mathrm{~mm}$

PETN booster explosive $p=1.6 \mathrm{~g} / \mathrm{cm}^{3}$

$9.6 \mathrm{~mm}$

$12.8 \mathrm{~mm}$

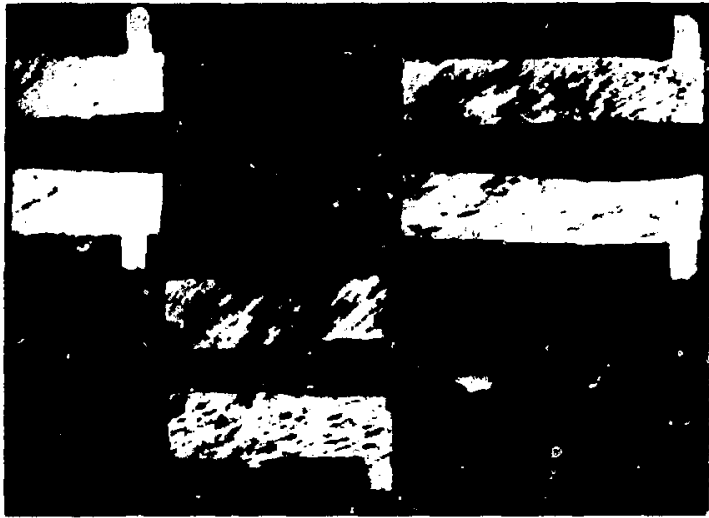

End confinement: $\quad 6061-\mathrm{T} 6$ sluminum slug Length: $\quad 6.4 \mathrm{~mm} \quad 9.6 \mathrm{~mm} \quad 12.8 \mathrm{~mm}$

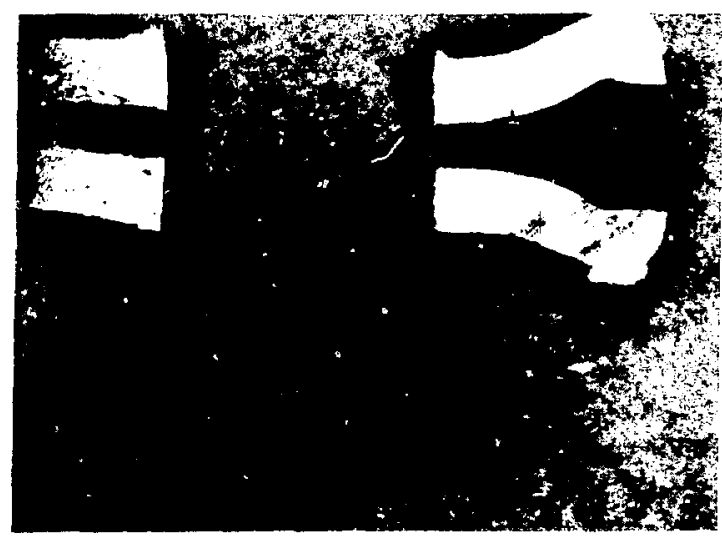
End confinement: PETN booster explosive $\left(p=1.6 \mathrm{~g} / \mathrm{cm}^{3}\right)+$ 2024 aluminum witness plate thickness $=19 \mathrm{~mm}$
Length: $\quad 6.4 \mathrm{~mm} \quad 9.6 \mathrm{~mm} \quad 12.8 \mathrm{~mm}$

Fig. 2.

Transition-exptosive test results. 
influenced by the downstream-end confinement of the PETN in the transition column.

When air or a taped 6061-T6 aluminum witness slug is placed against the downstream end of the transition explosive, there is no evidence that the $6.4 \mathrm{~mm}$-long steel transition column expanded. Because these explosive outputs dent witness slugs, we surmise that the lack of visible cylinder expansion indicates only very weak detonations. With transition-explosive lengths of 9.6 and $12.8 \mathrm{~mm}$, clear evidence of cylinder expansion in the DDT process occurs $\sim 8 \mathrm{~mm}$ downstream from the donor-ignition source.

Dent depths in the aluminum witness slugs were measured and plotted as a function of the macroscopic explosive-charge density. Surprisingly, the relationship (Fig. 3) shows a maximum for each transition-crslumn length, a phenomenon that we suspect is relateri to the porosity and density gradients in the pressed explosive.

In Fig. 3, $\mathbf{Y}$ and $\mathbf{N}$ denote whether a high-density booster pellet attached to the downstream end of the transition pressing was initiated to detonation. These data fall into two zones. Assemblies that produce dent depths greater than $\sim 0.5 \mathrm{~mm}$ in aluminum witness slugs will initiute PETN booster pellets; other assemblies will not. This relationship predicts that a transition-explosive charge of $6.4 \mathrm{~mm}$ length should not-and it does not-initiate PETN output pellets. We assume that dent depth is a measure of the detonation velocity achieved at the end of the DDT reaction column. The critical velocity value was calculated to be $\sim 3000 \mathrm{~m} / \mathrm{s}$. Dinegar's ${ }^{3}$ diameter correction and Kirkham's* density/detonation velocity relationship were used.

Deformation of the transition column is dramatic when a high-density $\left(1.6 \mathrm{~g} / \mathrm{cm}^{3}\right)$ PETN pellet is placed against the downstream end. Explosion of the output pellet is accompanied by considerable flaring of the end of the steel transition-explosive confiner. A 2024 aluminum witness block fixed against the downstream face of the pellet is dented $\sim 2 \mathrm{~mm}$, indicating explosive detonation at close to full velocity.

-John Yirkham. Atomic Weapons Research Establishment. Aldermaston. England, provided this information.

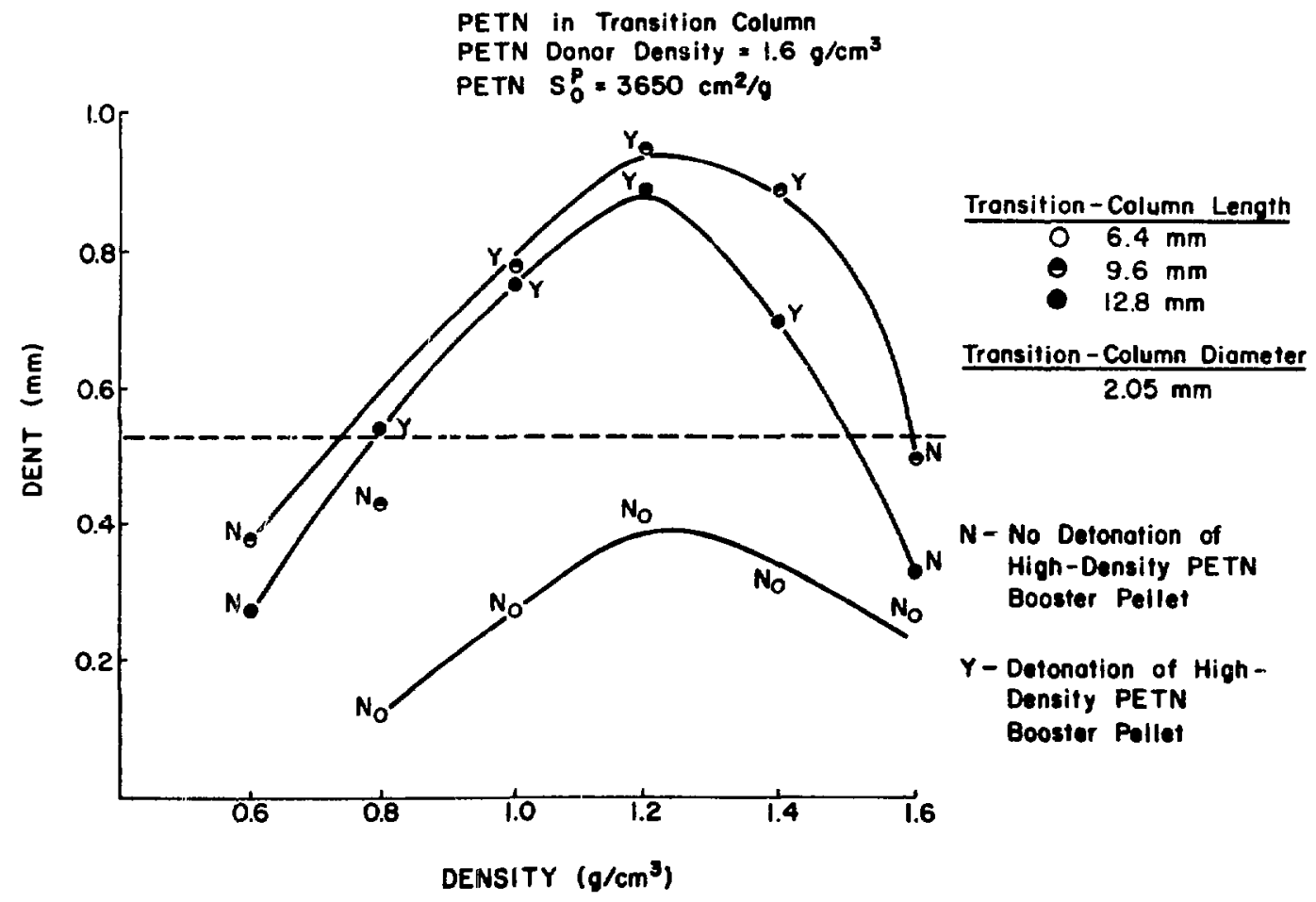

Fie. 3.

6061-T6 aluminum slus dent vis loadeas dencity. 


\section{REFERENCES}

1. Robert H. Dinegar, "The Ignition and Initiation of Potassium Picrate and Potassium Picrate/Explosives Mixtures: Nonprimary, Hot-Wire Detonators," Los Alamos National Laboratory report LA-7358-MS (August 1978).
2. Robert H. Dinegar and Daniel T. Varley III, "All-Secondary Explosive Hot-Wire Devices," Los Alamos National Laboratory report LA-7897-MS (October 1979).

3. Robert H. Dinegar, "Detonation Velocity of PETN in Small Confined Cylindrical Charges," Propellants and Explos. 1 (5/6), 97 (1976). 